\title{
Rate of Transfer of Phosphorus between Metal and Slag*
}

\author{
By Katsumi MORI, ${ }^{* *}$ Sadao DOI,*** Toshiyuki KANEKO ${ }^{* * * *}$ \\ and Yasuji KAWAI**
}

\section{Synopsis}

Rate of transfer of phosphorus from iron melt to slag and vice versa was measured at temperature from $1570^{\circ}$ to $1680^{\circ} \mathrm{C}$. The slags contained iron oxide and their basicity ranged from 0.57 to 1.76 .

The rate of dephosphorization by slag increased with slag basicity, while the rate of rephosphorization from slag decreased. The rate of rephosphorization increased with temperature but the effect of temperature on the dephosphorization was not noticeable.

These results were interpreted as the mass-transfer-controlled reaction. Mass transfer coefficients in the liquid iron phase were from $0.33 \times$ $10^{-2}$ to $1.09 \times 10^{-2} \mathrm{~cm} / \mathrm{sec}$ and in the slag phase from $0.47 \times 10^{-3}$ to $4.3 \times 10^{-3} \mathrm{~cm} / \mathrm{sec}$, at the experimental temperature range.

\section{Introduction}

It is well known that phosphorus is harmful for the mechanical properties of steels and much effort has been made to manufacture steels of lower phosphorus content. Most of phosphorus in iron can be removed by slag during oxidizing period of steelmaking. However, some quantity of phosphorus would be absorbed by molten steel from the slag in a ladle, when the deoxidizers are added after the converting process. If so, the dephosphorization in the converter becomes less effective.

Phosphorus equilibrium between liquid iron and slag has been studied by many investigators, while the kinetics of reactions involving phosphorus has been scarcely investigated. Thus, further studies must be made on the reaction kinetics between the metal and the slag to realize the more effective dephosphorization during steelmaking.

The present paper gives the result of an experimental study on the rate of dephosphorization and rephosphorization of molten steel at $1570^{\circ}$ to $1680^{\circ} \mathrm{C}$.

\section{Experimental Procedure}

After addition of the slag onto liquid iron contained in a magnesia crucible, samples were taken both from the iron and slag at an appropriate interval. The rate of dephosphorization or rephosphorization was determined from the change of phosphorus content in the samples. At the same time, the change of oxygen content of the metal was determined by the conventional analysis.

The furnace assembly used for the dephosphorization experiment is shown in Fig. 1. For some experiments on dephosphorization and for all experiments on rephosphorization, an electric-resistance heater was used instead of an induction heating coil shown in
Fig. 1.

The procedure of experiment on dephosphorization was as follows:

A $250 \mathrm{~g}$ of iron containing about $0.4 \% \mathrm{P}$ was melted in a fused magnesia crucible (I.D. $40 \mathrm{~mm}$ ) under argon gas atmosphere. After holding for a time at the experimental temperature of $1570^{\circ}$ to $1680^{\circ} \mathrm{C}$, a slag holder (iron crucible) containing $40 \mathrm{~g}$ slag was lowered to touch the liquid iron surface. The time, when the liquid slag in the holder flowed out, was taken as the beginning of the reaction. A graphite ring was fixed to the upper part of the crucible to heat the slag by the induction to the same temperature with liquid iron.

Temperature was measured by a $\operatorname{PtRh}(6 \%)-$ PtRh $(30 \%)$ thermocouple inserted from the bottom of the reaction chamber.

Samples were taken by sucking up the metal into silica tubes and by sticking slag to cold iron rods inserted through a sampling hole at the upper cap of the reaction chamber.

The procedure of rephosphorization experiment was

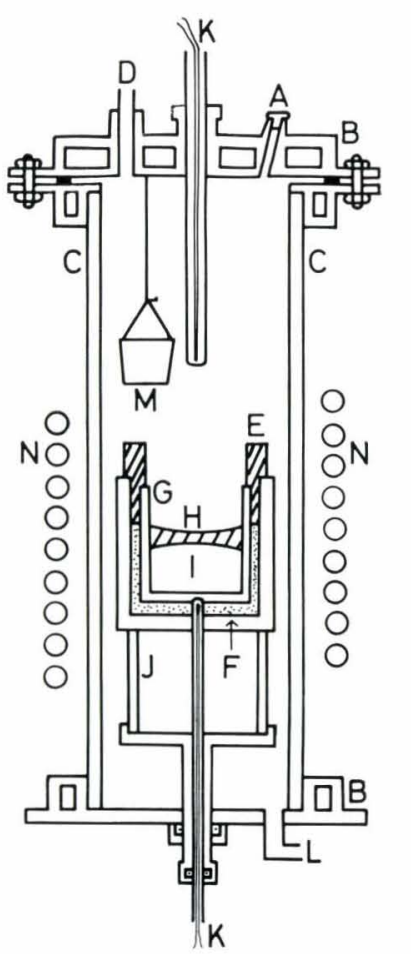

A: Sampling hole

B: Water-cooled cap

C: Silica tube

D: Gas inlet

E: Graphite ring

F: Protection crucible

$\mathrm{G}$ : $\mathrm{MgO}$ crucible

$\mathrm{H}$ : Slag

I: Metal

$\mathrm{J}$ : Supporter

$\mathrm{K}$ : Thermocouple

L: Gas outlet

M: Slag holder

$\mathrm{N}$ : Induction coil

* Originally published in Tetsu-to-Hagané, 63 (1977), 391, in Japanese. English version received May $16,1977$.

** Faculty of Engineering, Kyushu University, Hakozaki, Higashi-ku, Fukuoka 812.

*** Faculty of Engineering, Ehime University, Bunkyo-cho, Matsuyama 790.

**** Formerly Graduate School, Kyushu University. Now at Oita Works, Nippon Steel Corp., Nishinosu, Ohita 870. 
almost the same. However, the inner diameter of the crucible used was $30 \mathrm{~mm}$ and the weights of iron and slag were 180 and $20 \mathrm{~g}$, respectively.

The slags have the basicity range from 0.57 to 1.76. Slags were made from iron oxide prepared by decomposition of $\mathrm{Fe}(\mathrm{COO})_{2} \cdot 2 \mathrm{H}_{2} \mathrm{O}, \mathrm{CaO}, \mathrm{SiO}_{2}$ and $3 \mathrm{CaO} \cdot \mathrm{P}_{2} \mathrm{O}_{5}$. Mixtures of powders were melted in iron crucibles. Therefore, the slag compositions were restricted to those of low melting point and low basicity. The chemical composition of the slags is shown in Table 1.

\section{Experimental Results}

\section{Dephosphorization}

Experimental conditions and results are summarized in Table 2, including the temperature, reaction time, phosphorus and oxygen contents of liquid iron before and after the reaction, and the chemical composition of final slags.

Magnesia in the final slags originated from the magnesia crucible and the concentration was nearly equal to its solubility. The concentration of iron oxide decreased considerably during the run but the concentrations of $\mathrm{CaO}$ and $\mathrm{SiO}_{2}$ were almost unchanged. In spite of sampling losses, the quantity of slag seemed to be kept nearly constant probably due to the dissolution of magnesia. Therefore, the decrease of iron oxide would be compensated by the dissolution of magnesia into slag.
Figure 2 shows the change of the phosphorus and oxygen contents in iron during runs with "slag D" (basicity $=1.14$ ) and Figure 3 shows those with other slags at $1640^{\circ} \mathrm{C}$. As shown in these results, the dephosphorizing reaction by the slags proceeded very fast, and within about $10 \mathrm{~min}$, phosphorus in the metal reached constant values. The final contents were lower with the slags of higher basicity and higher iron oxide content at lower temperature. This agrees with the equilibrium distribution ratio of phosphorus

Table 2. Changes of phosphorus and oxygen content of liquid iron and composition of final slags (Dephosphorization)

\begin{tabular}{|c|c|c|c|c|c|c|c|c|c|c|c|c|}
\hline \multirow{2}{*}{ Slag } & \multirow{2}{*}{$\begin{array}{l}\text { Run } \\
\text { No. }\end{array}$} & \multirow{2}{*}{$\begin{array}{l}\text { Temp. } \\
\left({ }^{\circ} \mathbf{C}\right)\end{array}$} & \multirow{2}{*}{$\begin{array}{l}\text { Time } \\
(\mathrm{min})\end{array}$} & \multicolumn{2}{|c|}{$[\% \mathrm{P}]$} & \multicolumn{2}{|c|}{$[\% \mathrm{O}]$} & \multicolumn{5}{|c|}{ Final slag (\%) } \\
\hline & & & & Init. & Final & Init. & Final & T. Fe & $\mathrm{CaO}$ & $\mathrm{SiO}_{2}$ & $\mathrm{MgO}$ & $\mathrm{P}_{2} \mathrm{O}_{5}$ \\
\hline \multirow{5}{*}{$\mathrm{A}$} & $\mathrm{H}^{* 33}$ & 1.570 & 12 & 0.352 & 0.027 & 0.029 & & 22.8 & 38.3 & 22.2 & 3.5 & 4.9 \\
\hline & H 34 & 1640 & 15 & 0.374 & 0.030 & 0.034 & 0.155 & 22.8 & 35.7 & 21.9 & 6.5 & 5.4 \\
\hline & H 35 & 1680 & 12 & 0.417 & 0.046 & 0.029 & 0.166 & 20.1 & 37.9 & 22.2 & 6.9 & 6.2 \\
\hline & $\mathrm{R} * 13$ & 1540 & 11 & 0.359 & 0.058 & 0.042 & 0.142 & 21.9 & 37.6 & 22.3 & 3.8 & 5.3 \\
\hline & R 14 & 1595 & 11 & 0.412 & 0.053 & 0.039 & 0.154 & 21.7 & 37.4 & 22.3 & 5.0 & 4.8 \\
\hline \multirow{3}{*}{ B } & H 41 & 1570 & 14 & 0.330 & 0.027 & 0.032 & 0.139 & 31.0 & 28.0 & 21.2 & 6.4 & 4.4 \\
\hline & H 42 & 1640 & 19 & 0.430 & 0.069 & 0.031 & 0.171 & 25.6 & 27.7 & 22.1 & 11.8 & 5.5 \\
\hline & H 43 & 1680 & 20 & 0.439 & 0.058 & 0.031 & 0.188 & 26.8 & 27.6 & 22.1 & 10.9 & 5.4 \\
\hline \multirow{4}{*}{$\mathrm{C}$} & H 24 & 1570 & 11.5 & 0.407 & 0.180 & 0.026 & 0.064 & 11.9 & 39.1 & 34.2 & 9.0 & 3.3 \\
\hline & H 25 & 1640 & 11 & 0.401 & 0.158 & 0.027 & 0.073 & 10.0 & 38.5 & 32.5 & 10.7 & 3.2 \\
\hline & H 26 & 1680 & 11 & 0.444 & 0.223 & 0.025 & 0.083 & 9.0 & 38.0 & 31.5 & 12.9 & 3.7 \\
\hline & R 17 & 1595 & 12.5 & 0.747 & 0.500 & 0.031 & & 10.4 & 34.9 & 34.9 & 10.2 & 5.2 \\
\hline \multirow{5}{*}{ D } & H 38 & 1570 & 14 & 0.332 & 0.045 & 0.034 & 0.107 & 16.4 & 35.2 & 28.8 & 10.1 & 3.5 \\
\hline & H 39 & 1640 & 14 & 0.361 & 0.064 & 0.028 & 0.115 & 16.0 & 35.0 & 29.1 & 10.9 & 3.8 \\
\hline & H 40 & 1680 & 15 & 0.364 & 0.109 & 0.039 & 0.125 & 13.5 & 33.9 & 29.4 & 13.5 & 3.7 \\
\hline & R 11 & 1540 & 14 & 0.388 & 0.109 & 0.070 & 0.113 & 18.1 & 33.0 & 28.0 & 10.1 & 3.8 \\
\hline & R 12 & 1595 & 14 & 0.388 & 0.117 & 0.082 & 0.127 & 19.4 & 31.9 & 26.6 & 11.3 & 3.7 \\
\hline \multirow{5}{*}{$\mathrm{E}$} & H 27 & 1570 & 15.5 & 0.443 & 0.167 & 0.025 & 0.123 & 27.0 & 16.7 & 27.3 & 13.2 & 3.3 \\
\hline & H 28 & 1640 & 14.5 & 0.413 & 0.223 & 0.025 & 0.135 & 24.3 & 16.5 & 27.9 & 18.2 & 3.4 \\
\hline & H 29 & 1680 & 12.5 & 0.407 & 0.208 & & 0.099 & 23.9 & 17.3 & 27.0 & 17.5 & 3.3 \\
\hline & R 9 & 1540 & 12 & 0.351 & 0.180 & 0.078 & 0.133 & 29.0 & 16.1 & 26.2 & 15.6 & 2.4 \\
\hline & $\mathrm{R} 10$ & 1595 & 11.5 & 0.300 & 0.214 & 0.102 & 0.162 & 27.8 & 15.1 & 25.0 & 17.0 & 2.4 \\
\hline
\end{tabular}

* $\mathrm{H}$ and $\mathrm{R}$ indicate the run in a H.F. induction furnace and in a $\mathrm{SiC}$ resistance furnace, respectively. 


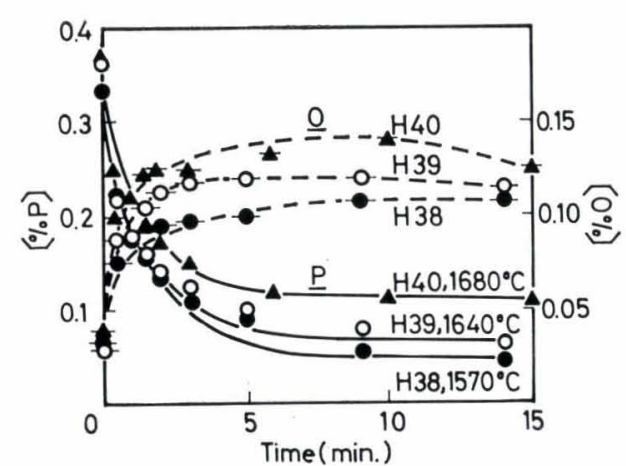

Fig. 2. Changes of phosphorus and oxygen contents during runs (Slag D)

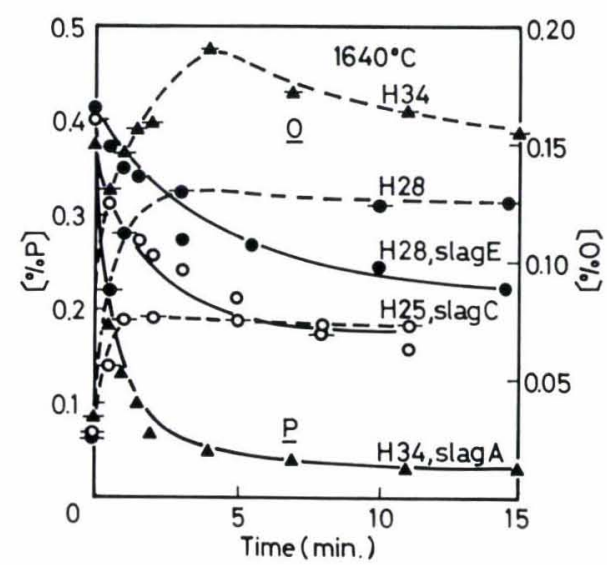

Fig. 3. Changes of phosphorus and oxygen contents in the iron under various slags at $1640^{\circ} \mathrm{C}$

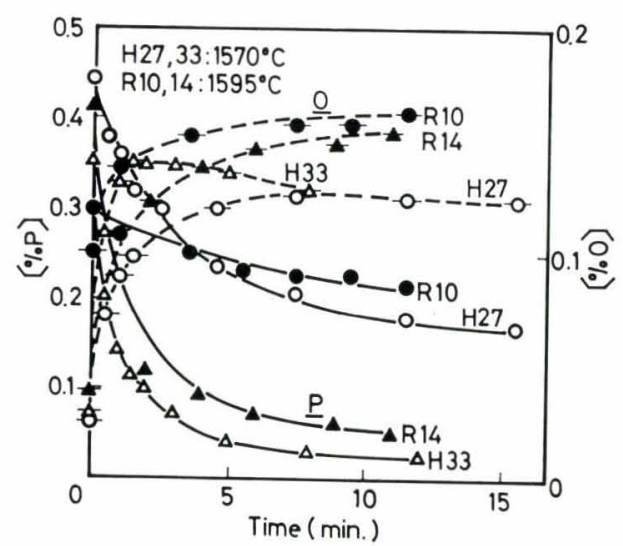

Fig. 4. Changes of phosphorus and oxygen contents in the iron in a high frequency induction furnace $(\mathrm{H} 27,33)$ and in a resistance furnace $(\mathrm{R} 10,14)$

given by previous investigators.

The reaction rate of dephosphorization increased with increase of slag basicity as shown in Fig. 3, but the influence of temperature on the reaction rate was not clearly observed in Fig. 2.

The transfer of oxygen from the slag to the metal is also so fast as shown in Figs. 2 and 3. It was frequently observed that oxygen in iron decreased after reaching the maximum. This observation was presumably due to the decrease of the activity of iron oxide in slag with progress of the dephosphorizing reaction and dissolution of $\mathrm{MgO}$. This suggests that the rate of transfer of oxygen from the slag to the metal is higher than that of phosphorus.

In Fig. 4, the experimental results obtained in the resistance furnace are compared with those in the induction furnace to show the effect of agitation of liquid iron on the reaction rate. It seems that the reaction rate is low in a resistance furnace. However, this is probably due to the difference in the driving force for the reaction and if so, the rate constant (mass transfer coefficient) would be nearly the same as shown later.

\section{Rephosphorization}

Experimental conditions and chemical composition of final slags are shown in Table 3. In this case, the decrease of iron oxide in slag during the run was not so much as in the case of dephosphorization.

Figure 5 shows the changes of phosphorus and oxygen contents of liquid iron at about $1600^{\circ} \mathrm{C}$ with various slags and Figure 6 shows the effect of temperature with "slag H" (basicity=1.38). From these results, it is found that the rephosphorizing reaction proceeds also very fast and the phosphorus content in the metal becomes constant after about $20 \mathrm{~min}$. The final content is lower with more basic slag and at lower temperature, corresponding to the distribution ratio of phosphorus between the metal and the slag. The reaction rate of rephosphorization was large in the case of acid slag at high temperature. The concentration of initial oxygen in the metal seemed to have little effect on the reaction rate.

\section{Discussion}

\section{Distribution of Phosphorus between Iron and Slag}

It is necessary for the study of reaction kinetics to know the driving force for the reaction. There are many studies on the equilibrium distribution of phosphorus between iron melt and slag, but the reliable expression of the equilibrium is not yet obtained, because of the experimental difficulties. The simple equation derived by Turkdogan and Pearson ${ }^{1)}$ was found to be inadequate, because values of the equilibrium constant defined by $\mathrm{N}_{\mathrm{P}_{2} \mathrm{O}_{5}} / a_{\mathrm{P}}^{2} \cdot a_{0}^{5}$ calculated from their equation were lower by about two order than those calculated from the final phosphorus and oxygen contents in the present experiments. This suggests that the equation given by Turkdogan and Pearson cannot be applied to the wide range of slag composition.

Recently, Healy ${ }^{2)}$ presented another simple equation for the phosphorus distribution from the viewpoint of ionic theory of slag as follows:

$$
\begin{gathered}
\log L_{\mathrm{P}}\left(=\frac{(\% \mathrm{P})}{[\% \mathrm{P}]}\right)=\frac{22350}{T}+0.08(\% \mathrm{CaO}) \\
+2.5 \log (\% \mathrm{~T} . \mathrm{Fe})-16.0
\end{gathered}
$$

As shown in Fig. 7, values of $L_{\mathrm{P}}$ calculated from Eq. (1) are in a good accordance with the present experiments. Thus, Eq. (1) was employed in the 
Table. 3. Changes of phosphorus and oxygen content of liquid iron and composition of final slags (Rephosphorization)

\begin{tabular}{|c|c|c|c|c|c|c|c|c|c|c|c|c|}
\hline \multirow{2}{*}{ Slag } & \multirow{2}{*}{$\begin{array}{l}\text { Run } \\
\text { No. }\end{array}$} & \multirow{2}{*}{$\begin{array}{l}\text { Temp. } \\
\left({ }^{\circ} \mathrm{C}\right)\end{array}$} & \multirow{2}{*}{$\begin{array}{l}\text { Time } \\
(\mathrm{min})\end{array}$} & \multicolumn{2}{|c|}{$[\% \mathrm{P}]$} & \multicolumn{2}{|c|}{$[\% \mathrm{O}]$} & \multicolumn{5}{|c|}{ Final slag (\%) } \\
\hline & & & & Init. & Final & Init. & Final & T. Fe & $\mathrm{CaO}$ & $\mathrm{SiO}_{2}$ & $\mathrm{MgO}$ & $\mathrm{P}_{2} \mathrm{O}_{5}$ \\
\hline \multirow{2}{*}{$\mathrm{F}$} & G 20 & 1575 & 20 & 0.010 & 0.056 & 0.034 & 0.171 & 34.2 & & & & 3.9 \\
\hline & G 19 & 1595 & $”$ & 0.009 & 0.062 & 0.029 & 0.171 & 32.6 & & & & 4.0 \\
\hline G & E 7 & 1595 & $”$ & 0.010 & 0.064 & 0.072 & 0.180 & 34.7 & 25.2 & 16.9 & 8.1 & 4.5 \\
\hline \multirow{2}{*}{$\mathrm{H}$} & G $\quad 1$ & 1570 & $"$ & 0.007 & 0.049 & 0.057 & 0.148 & 34.7 & 23.0 & 16.7 & 9.4 & 5.5 \\
\hline & G 3 & 1640 & $"$ & 0.007 & 0.078 & 0.057 & 0.189 & 33.8 & 23.7 & 17.2 & 9.7 & 5.2 \\
\hline I & E 21 & 1615 & $"$ & 0.007 & 0.141 & 0.061 & 0.174 & 50.9 & 11.9 & 11.5 & 7.5 & 3.6 \\
\hline \multirow{3}{*}{$\mathrm{J}$} & G 4 & 1570 & $"$ & 0.006 & 0.081 & 0.075 & 0.135 & 29.7 & 23.5 & 27.5 & 10.2 & 4.6 \\
\hline & G 5 & 1600 & , & 0.008 & 0.087 & 0.097 & 0.177 & & & & & 3.7 \\
\hline & G 6 & 1650 & $"$ & 0.008 & 0.115 & 0.103 & 0.197 & & & & & 3.8 \\
\hline \multirow{2}{*}{$\mathrm{K}$} & E 5 & 1595 & $"$ & 0.006 & 0.099 & 0.076 & 0.162 & 26.9 & 18.5 & 23.4 & 18.3 & 4.7 \\
\hline & E 17 & 1595 & $”$ & 0.007 & 0.097 & 0.153 & 0.162 & 28.6 & 15.1 & 21.5 & 19.8 & 4.4 \\
\hline $\mathrm{L}$ & E 2 & 1600 & $"$ & 0.006 & 0.108 & 0.086 & 0.115 & 17.8 & 19.1 & 32.4 & 23.6 & 1.6 \\
\hline M & E 20 & 1610 & ” & 0.007 & 0.171 & 0.046 & 0.105 & 19.2 & 17.7 & 30.3 & 25.6 & 1.4 \\
\hline $\mathrm{N}$ & G 8 & 1600 & $"$ & 0.008 & 0.071 & 0.082 & 0.145 & 23.6 & 16.7 & 29.2 & 21.9 & 1.4 \\
\hline
\end{tabular}

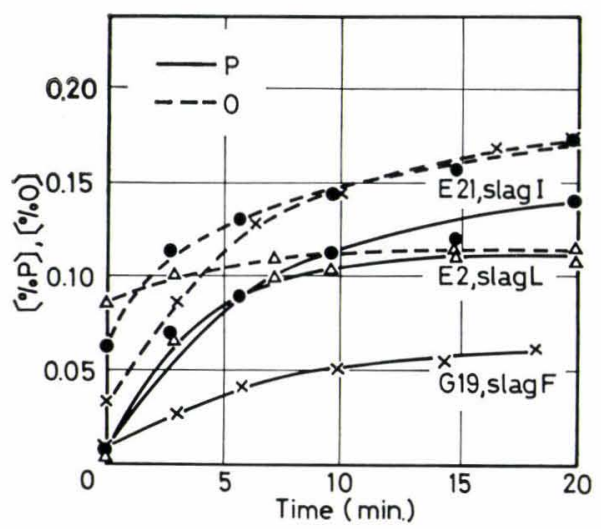

Fig. 5. Changes of phosphorus and oxygen contents during runs at about $1600^{\circ} \mathrm{C}$

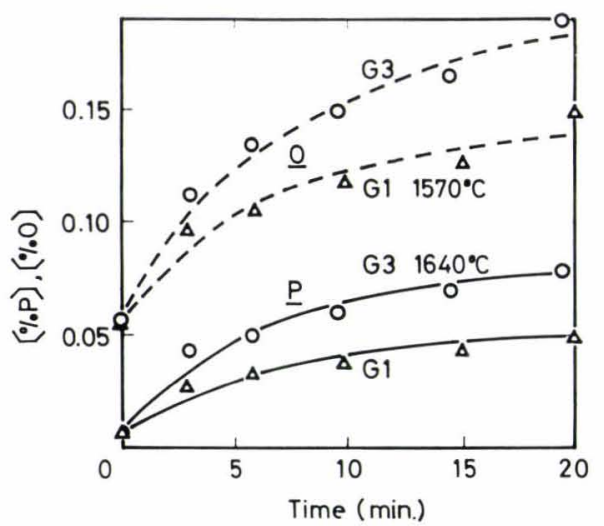

Fig. 6. Changes of phosphorus and oxygen contents during runs (Slag $\mathrm{H})$

followings to examine the reaction rate of phosphorus between iron and slag, although other slag components than lime and iron oxide are neglected in the equation.

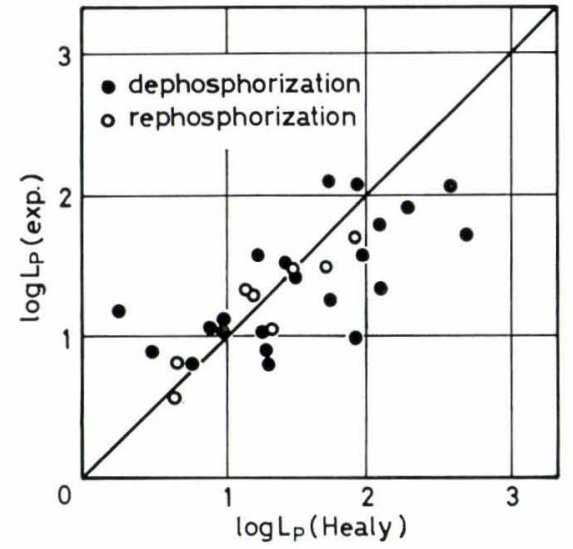

Fig. 7. Distribution ratio of phosphorus plotted against equilibrium values

2. Rate of Transfer of Phosphorus between Iron and Slag

Transfer of phosphorus across the metal-slag interface would proceed with electrochemical reactions as follows :

$$
\begin{aligned}
& \underline{\mathrm{P}}=\mathrm{P}^{5+}+5 e \\
& \mathrm{O}^{2-}=\underline{\mathrm{O}}+2 e \\
& \mathrm{Fe}=\mathrm{Fe}^{2+}+2 e, \mathrm{Fe}^{2+}=\mathrm{Fe}^{3+}+e
\end{aligned}
$$

The amount of transferred phosphorus must satisfy the following relation to keep the electro-neutrality of the system.

$$
5 \Delta n_{\mathrm{P}}=2 \Delta n_{\mathrm{O}}+2 \Delta n_{\mathrm{Fe}^{2+}}+3 \Delta n_{\mathrm{Fe}^{3+}}
$$

where $\Delta n$ is number of transferred ions.

This was examined with the experimental results of rephosphorization. The increase of phosphorus in the metal was nearly equal to the sum of the increase of oxygen in metal and iron in slag as shown in Fig. 8. 


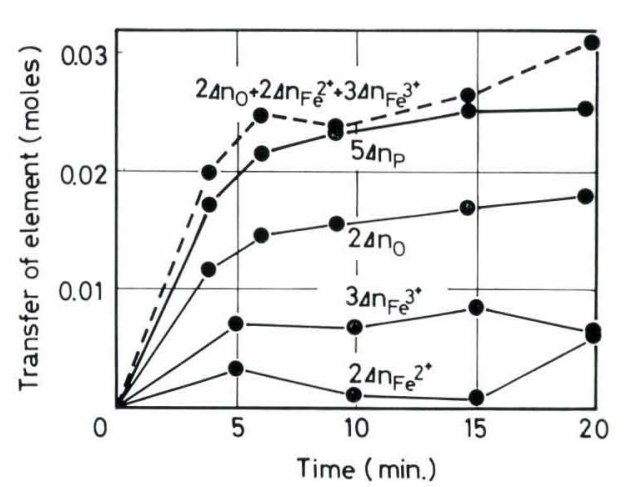

Fig. 8. Mass balance for Run E 5 (rephosphorization)

When many reactions proceed simultaneously, it is usually difficult to determine the rate-controlling step. Aratani and Sanbongi ${ }^{3)}$ proposed that the chemical reaction at the interface was the rate-controlling step in the dephosphorizing reaction by slag, but the chemical equation was not given in their report.

Generally speaking, the rate of chemical reaction at high temperature is higher than that of mass transfer of reaction species to and from the reaction site. Thus, the present results were analyzed on the assumption that the reaction was controlled by the mass transfer step. As described in the above, the oxygen content of liquid iron frequently decreased after reaching the maximum during the run. This indicates that the rate of transfer of oxygen is high comparing with that of phosphorus.

When the transfer of phosphorus in the slag controls the reaction rate, the rate equation can be expressed by

$$
\frac{d[\% \mathrm{P}]}{d t}=\frac{A}{W_{\mathrm{m}}} \rho_{\mathrm{s}} k_{\mathrm{s}}\left\{(\% \mathrm{P})-L_{\mathrm{P}}[\% \mathrm{P}]\right\}
$$

When the rate-controlling step is in the metal phase,

$$
\frac{d[\% \mathrm{P}]}{d t}=\frac{A}{W_{\mathrm{m}}} \rho_{\mathrm{m}} k_{\mathrm{m}}\left\{\frac{(\% \mathrm{P})}{L_{\mathrm{P}}}-[\% \mathrm{P}]\right\}
$$

where, $A$ : the interfacial area

$W_{\mathrm{m}}$ : the weight of metal

$\rho_{\mathrm{s}}, \rho_{\mathrm{m}}$ : densities of slag and metal

$k_{\mathrm{s}}, k_{\mathrm{m}}$ : mass transfer coefficients in slag and metal.

Strictly speaking, the mass flux of one component in multicomponent system like the present slag should be affected by the concentration differences of other components and thus, must be described by the equation containing these terms. However, it is difficult to express quantitatively such an effect because of the lack of necessary data. Therefore, in the present paper, the rate equation was expressed as Eq. (3) by applying the film theory with binary diffusion.

During the period from $n$-th to $(n+1)$-th sampling, the following mass balance relation should hold:

$$
W_{\mathrm{m} n}[\% \mathrm{P}]_{n}+W_{\mathrm{s} n}(\% \mathrm{P})_{n}=W_{\mathrm{m} n}[\% \mathrm{P}]+W_{\mathrm{s} n}(\% \mathrm{P}) \ldots(5)
$$

$$
\begin{aligned}
& (\% \mathrm{Fe})_{n}-(\% \mathrm{Fe})=\frac{5 M_{\mathrm{Fe}} W_{\mathrm{m} n}}{2 M_{\mathrm{P}} W_{\mathrm{s} n}}\left\{[\% \mathrm{P}]_{n}-[\% \mathrm{P}]\right\} \\
& -\frac{M_{\mathrm{Fe}} W_{\mathrm{m} n}}{M_{\mathrm{o}} W_{\mathrm{s} n}}\left\{[\% \mathrm{O}]_{n}-[\% \mathrm{O}]\right\}
\end{aligned}
$$

where, $W_{\mathrm{s}}$ : the weight of slag

$M:$ the atomic weight.

Substituting (\%P) from Eq. (5) into Eqs. (3) and (4) and expressing as the sum of integrals, one has

$$
\begin{aligned}
& \sum_{n} \int_{[\% \mathrm{P}]_{n}}^{[\% \mathrm{P}]_{n+1}}\left[W_{\mathrm{m} n} /\left\{\left(W_{\mathrm{m} n} / W_{\mathrm{s} n}\right)[\% \mathrm{P}]_{n}+(\% \mathrm{P})_{n}\right.\right. \\
& \left.\left.\quad-\left(L_{\mathrm{P}}+W_{\mathrm{m} n} / W_{\mathrm{s} n}\right)[\% \mathrm{P}]\right\}\right] \cdot d[\% \mathrm{P}]=A \cdot \rho_{\mathrm{s}} k_{\mathrm{s}} \cdot t \ldots \\
& \sum_{n} \int_{\left[\% \mathrm{P}_{n}\right.}^{[\% \mathrm{P}]_{n+1}}\left[W_{\mathrm{m} n} L_{\mathrm{P}} /\left\{\left(W_{\mathrm{m} n} / W_{\mathrm{s} n}\right)[\% \mathrm{P}]_{n}+(\% \mathrm{P})_{n}\right.\right. \\
& \left.\left.\quad-\left(L_{\mathrm{P}}+W_{\mathrm{m} n} / W_{\mathrm{s} n}\right)[\% \mathrm{P}]\right\}\right] \cdot d[\% \mathrm{P}]=A \cdot \rho_{\mathrm{m}} k_{\mathrm{m}} \cdot t \ldots
\end{aligned}
$$

The present results were analyzed by using above Eqs. (7) and (8). The distribution ratio $L_{\mathrm{P}}$ and the mass transfer coefficients $k_{\mathrm{s}}$ and $k_{\mathrm{m}}$ were determined from the numerical calculation by a computer so as to hold the linear relation between the sum of integrals and time.

In the calculation, the following assumptions were used :

(1) In the case of dephosphorization, the reaction is controlled by the transfer of phosphorus from the metal-slag interface to the bulk slag, because the effect of agitation of the liquid metal on the reaction rate was small.

(2) In the case of rephosphorization, the reaction was assumed to be controlled by the transfer of phosphorus from the metal-slag interface to the bulk metal.

In the case of dephosphorizatoin, the amount of slag $W_{\mathrm{s}}$ was kept constant during a run, while the amount of metal $W_{\mathrm{m}}$ decreased by sampling. Distribution ratio of phosphorus $L_{\mathrm{P}}$ varied during a run according to Eq. (9), which is a more simplified form of Eq. (1):

$$
L_{\mathrm{P}}=a(\% \mathrm{~T} . \mathrm{Fe})^{2.5}
$$

where $a$ was constant and regarded as a parameter instead of $L_{\mathrm{P}}$ in the calculation. Values of $(\% \mathrm{P})$ and $(\% \mathrm{~T} . \mathrm{Fe})$ were calculated by Eqs. (5) and (6). Density of slag was assumed to be constant. Examples of the result of calculations on dephosphorization are shown in Fig. 9 (a).

In the case of rephosphorization, the assumption of (2) was found to be adequate from the independency of $k_{\mathrm{m}}$ on $L_{\mathrm{P}}$ and from the lower value of the activation energy as shown later. The distribution ratio, $L_{\mathrm{P}}$ was assumed to be constant during the run, because the change of the slag composition was little. The change of metal and slag quantities caused by sampling was taken into account in the calculation. Examples of the result of calculations on rephosphorization are shown in Fig. 9 (b).

Values of calculated mass transfer coefficients $k_{\mathrm{s}}$ and $k_{\mathrm{m}}$ are given in Tables 4 and 5 . Also, values of distribution ratio $L_{\mathrm{P}}$ are given in the same tables in comparison with those obtained experimentally, which 
are in good accordance with each other. Values of $k_{\mathrm{s}}$ are from $0.47 \times 10^{-3}$ to $4.3 \times 10^{-3} \mathrm{~cm} / \mathrm{sec}$ and $k_{\mathrm{m}}$ from $0.33 \times 10^{-2}$ to $1.09 \times 10^{-2} \mathrm{~cm} / \mathrm{sec}$. Values of $k_{\mathrm{m}}$ are nearly equal to those obtained by Klein et $a l .^{5)}$ for the rate of oxidation of $\mathrm{Si}, \mathrm{Al}$ and $\mathrm{Mn}$ in liquid iron
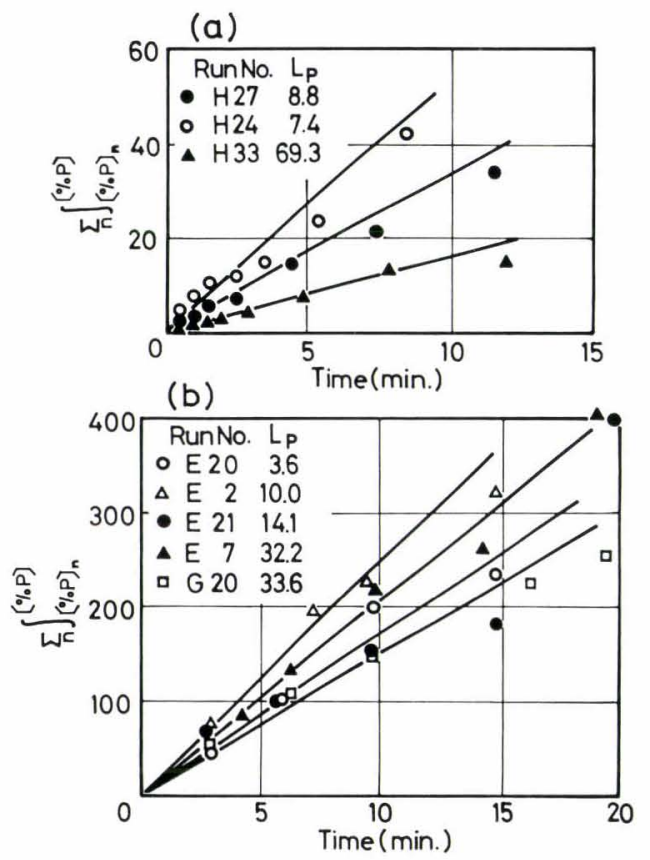

Fig. 9. Relation between integral value and reaction time calculated from Eqs. (7) and (8)

Table 4. Distribution ratio and mass-transfer-coefficient of phosphorus

\begin{tabular}{|c|c|c|c|c|c|}
\hline \multirow{2}{*}{ Slag } & \multirow{2}{*}{$\begin{array}{l}\text { Run } \\
\text { No. }\end{array}$} & \multirow{2}{*}{$\begin{array}{c}\text { Temp. } \\
\left({ }^{\circ} \mathbf{C}\right)\end{array}$} & \multicolumn{2}{|c|}{$L_{\mathrm{P}}$} & \multirow{2}{*}{$k_{\mathrm{s}}(\mathrm{cm} / \mathrm{sec})$} \\
\hline & & & Exp. & Calc. & \\
\hline \multirow{5}{*}{ A } & H 33 & 1570 & 74.0 & 69.3 & 0.00068 \\
\hline & H 34 & 1640 & 60.4 & 69.0 & 0.0012 \\
\hline & H 35 & 1680 & 49.1 & 46.0 & 0.0015 \\
\hline & R 13 & 1540 & 37.9 & 36.8 & 0.00061 \\
\hline & R 14 & 1595 & 39.7 & 38.3 & 0.00076 \\
\hline \multirow{3}{*}{ B } & H 41 & 1570 & 62.0 & 55.4 & 0.00047 \\
\hline & H 42 & 1640 & 33.4 & 30.2 & 0.0016 \\
\hline & H 43 & 1680 & 38.5 & 28.1 & 0.0018 \\
\hline \multirow{4}{*}{$\mathrm{C}$} & H 24 & 1570 & 7.6 & 7.4 & 0.0024 \\
\hline & H 25 & 1640 & 8.9 & 7.3 & 0.0026 \\
\hline & H 26 & 1680 & 5.8 & 5.6 & 0.0043 \\
\hline & R 17 & 1595 & 7.9 & 7.2 & 0.0015 \\
\hline \multirow{5}{*}{$\mathrm{D}$} & H 38 & 1570 & 36.9 & 34.0 & 0.00089 \\
\hline & H 39 & 1640 & 28.3 & 26.1 & 0.0014 \\
\hline & H 40 & 1680 & 13.9 & 12.9 & 0.0024 \\
\hline & R 11 & 1540 & 20.8 & 14.5 & 0.00078 \\
\hline & R 12 & 1595 & 18.9 & 10.8 & 0.0012 \\
\hline \multirow{5}{*}{ E } & H 27 & 1570 & 8.9 & 8.8 & 0.0013 \\
\hline & H 28 & 1640 & 7.1 & 5.4 & 0.0016 \\
\hline & H 29 & 1680 & 5.7 & 5.7 & 0.0032 \\
\hline & $\mathrm{R} \quad 9$ & 1540 & 6.9 & 4.8 & 0.0013 \\
\hline & R 10 & 1595 & 3.3 & 2.8 & 0.0016 \\
\hline
\end{tabular}

by slag in a Tamman furnace $\left(k_{\mathrm{m}}=0.2 \sim 1.4 \times\right.$ $10^{-2} \mathrm{~cm} / \mathrm{sec}$ ).

Solid curves in Figs. 2 to 6 of the phosphorus content in the metal are based upon the calculated values of $k_{\mathrm{s}}, k_{\mathrm{m}}$ and $L_{\mathrm{P}}$, but well agree with the experimental results.

If the reaction rate is controlled by both mass transfers in slag and metal, rate equations for dephosphorization and rephosphorization are, respectively

$$
\begin{aligned}
\frac{d[\% \mathrm{P}]}{d t}= & \frac{A}{W_{\mathrm{m}}} \frac{1}{\left(1 / \rho_{\mathrm{s}} k_{\mathrm{s}}^{\circ}+L_{\mathrm{P}} / \rho_{\mathrm{m}} k_{\mathrm{m}}^{\circ}\right)} \\
& \times\left\{(\% \mathrm{P})-L_{\mathrm{P}}[\% \mathrm{P}]\right\} \quad \ldots \ldots \\
\frac{d[\% \mathrm{P}]}{d t}= & \frac{A}{W_{\mathrm{m}}} \frac{1}{\left(1 / \rho_{\mathrm{m}} k_{\mathrm{m}}^{\circ}+1 / L_{\mathrm{P}} \rho_{\mathrm{s}} k_{\mathrm{s}}^{\circ}\right)} \\
& \times\left\{\frac{(\% \mathrm{P})}{L_{\mathrm{P}}}-[\% \mathrm{P}]\right\} \ldots \ldots \ldots . .
\end{aligned}
$$

Because the term of the driving force for mass transfer in Eqs. (3) and (10) is same and also in Eqs. (4) and (11), the mass transfer coefficients must be equal with each other. Therefore, if the terms of mass transfer coefficient in Eqs. (3) and (4) are equal to $1 / \rho_{\mathrm{s}} k_{\mathrm{s}}^{\circ}$ and $1 / \rho_{\mathrm{m}} k_{\mathrm{m}}^{\circ}$ in Eqs. (10) and (11), then the reaction was controlled by a single step. Values of $1 / \rho_{\mathrm{s}} k_{\mathrm{s}}$ obtained from Eq. (3) were plotted against $L_{\mathrm{P}}$ and $1 / \rho_{\mathrm{m}} k_{\mathrm{m}}$ from Eq. (4) against $1 / L_{\mathrm{P}}$ in Fig. 10 .

In the case of dephosphorization (the upper part of Fig. 10), an increasing tendency of $1 / \rho_{\mathrm{s}} k_{\mathrm{s}}$ with $L_{\mathrm{P}}$ is observed. This suggests that the resistance in the metal phase $\left(L_{\mathrm{P}} / \rho_{\mathrm{m}} k_{\mathrm{m}}^{\circ}\right)$ has an influence on the transfer of phosphorus and cannot be neglected, in particular at higher value of $L_{\mathrm{P}}$. In the case of rephosphorization (the lower part of Fig. 10), values of $1 / \rho_{\mathrm{m}} k_{\mathrm{m}}$ seem to be nearly constant. This shows

\begin{tabular}{|c|c|c|c|c|c|}
\hline \multirow{2}{*}{ Slag } & \multirow{2}{*}{$\begin{array}{l}\text { Run } \\
\text { No. }\end{array}$} & \multirow{2}{*}{$\begin{array}{l}\text { Temp. } \\
\left({ }^{\circ} \mathrm{C}\right)\end{array}$} & \multicolumn{2}{|c|}{$L_{\mathrm{P}}$} & \multirow{2}{*}{$k_{\mathrm{m}}(\mathrm{cm} / \mathrm{sec})$} \\
\hline & & & Exp. & Calc. & \\
\hline \multirow{2}{*}{$\mathrm{F}$} & G 20 & 1575 & 30.0 & 33.6 & 0.0051 \\
\hline & G 19 & 1600 & 28.2 & 31.6 & 0.0075 \\
\hline G & E 7 & 1595 & 31.0 & 32.2 & 0.0069 \\
\hline \multirow{2}{*}{$\mathrm{H}$} & G $\quad 1$ & 1570 & 49.7 & 54.1 & 0.0072 \\
\hline & G 3 & 1640 & 29.5 & 30.7 & 0.0077 \\
\hline I & E 21 & 1615 & 11.2 & 14.1 & 0.0058 \\
\hline \multirow{3}{*}{$\mathrm{J}$} & G 4 & 1570 & 24.7 & 29.1 & 0.0075 \\
\hline & G 5 & 1600 & 18.8 & 26.0 & 0.0068 \\
\hline & G 6 & 1650 & 14.3 & 18.0 & 0.0085 \\
\hline \multirow{2}{*}{$\mathrm{K}$} & E 5 & 1595 & 20.7 & 23.6 & 0.0096 \\
\hline & E 17 & 1595 & 19.6 & 22.6 & 0.0109 \\
\hline $\mathrm{L}$ & E 2 & 1600 & 6.4 & 10.0 & 0.0089 \\
\hline M & E 20 & 1610 & 3.7 & 3.6 & 0.0060 \\
\hline $\mathrm{N}$ & G 8 & 1600 & 8.8 & 10.6 & 0.0033 \\
\hline
\end{tabular}
that the resistance in the slag phase may be negligibly

Table 5. Distribution ratio and mass-transfer-coefficient of phosphorus 

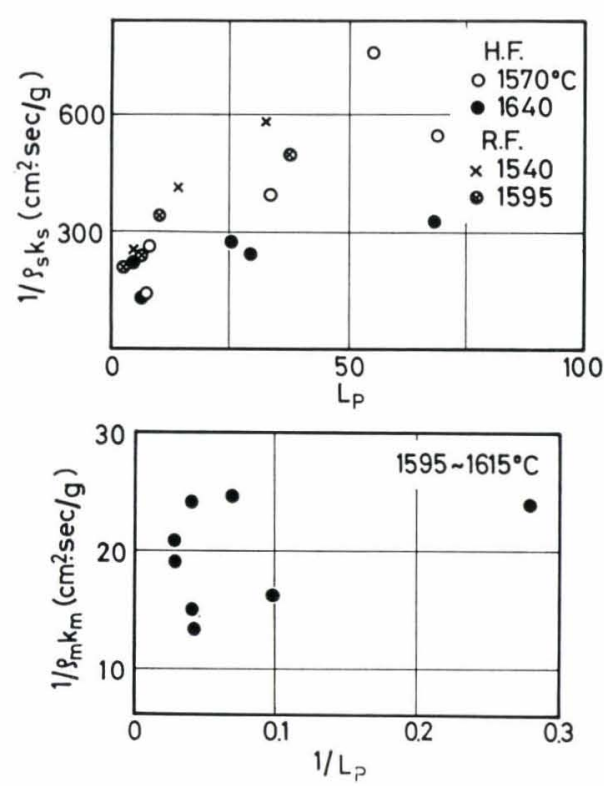

Fig. 10. Relation between mass-transfer-coefficient and distribution ratio

small.

\section{Effect of Slag Composition on the Rate of Transfer}

As described before, the rate of transfer of phosphorus from the metal to the slag increased with the slag basicity and that from the slag to the metal decreased. However, any meaningful relation was not found between the mass transfer coefficient and the slag basicity.

Viscosity of the slags used in the experiments is nearly the same according to the report of Kozakevitch. ${ }^{4}$ ) Diffusion coefficient of phosphorus in the slag has never been measured, but perhaps it would not change so much with slag composition. So, the change of mass transfer coefficient $k_{\mathrm{s}}$ with slag composition may be little as seen in Table 4.

From the present results, it may be concluded that the main factor influencing the rate of phosphorus transfer is the difference of the driving force of the diffusion and not that of diffusion coefficient.

\section{Effect of Temperature on the Reaction Rate}

The mass transfer coefficients $k_{\mathrm{s}}$ and $k_{\mathrm{m}}$ increased with temperature as shown in Fig. 11. Apparent activation energies were estimated about 40 and $10 \mathrm{kcal} / \mathrm{mol}$, respectively.

In spite of the increase of the mass transfer coefficient, the reaction rate of dephosphorization did not increase with temperature. This is due to the decrease of the driving force, that is, the decrease of distribution ratio of phosphorus with temperature. On the contrary, in the case of rephosphorization the distribution ratio (driving force) changed with temperature favorably for the proceeding of the reaction. Thus the effect of temperature on the reaction rate was observed clearly.

\section{Rate of Transfer of Oxygen from Slag to Metal}

Oxygen transfers from the slag to the metal simul-
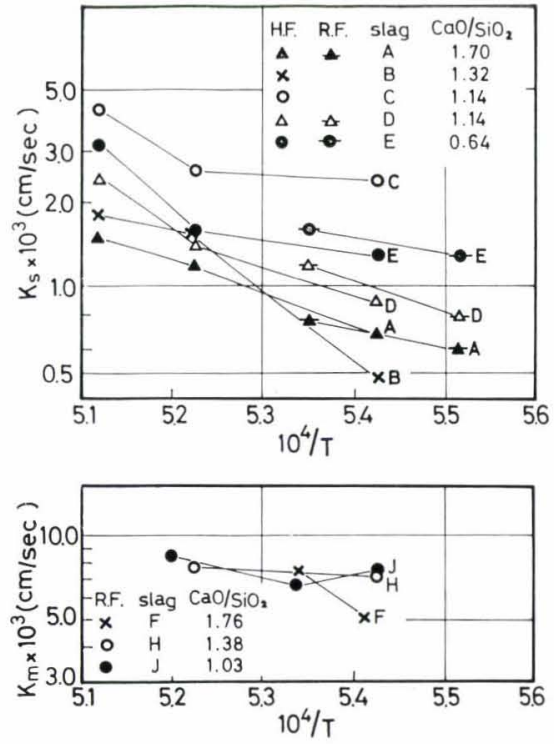

Fig. 11. Effect of temperature on the mass-transfer-coefficients

taneously with phosphorus as shown in Figs. 2 to 6 and this oxygen transfer may have some influences on the rate of the phosphorus reactions. To examine this effect, the rate of transfer of oxygen was measured with the metal and the slag containing no phosphorus under the same experimental condition as the rephosphorization experiment.

From the result, it was found that the rate of transfer of oxygen was controlled by the transfer in the metal phase as in the rephosphorization process.

The rate equation is expressed by

$$
\frac{d[\% \mathrm{O}]}{d t}=\frac{A}{W_{\mathrm{m}}} \rho_{\mathrm{m}} k_{\mathrm{o}}\left([\% \mathrm{O}]_{c}-[\% \mathrm{O}]\right)
$$

where, $k_{0}$ is the mass transfer coefficient and $[\% \mathrm{O}]$. is the equilibrium value. For the estimation of mass transfer coefficient, the final oxygen content, $[\% \mathrm{O}]_{f}$ was used instead of $[\% \mathrm{O}]_{e}$. From the linear relation between logarithms of $\left([\% \mathrm{O}]_{f}-[\% \mathrm{O}]\right)$ and time in Fig. 12, the mass transfer coefficient was obtained as $0.9 \times 10^{-2} \mathrm{~cm} / \mathrm{sec}$ at $1595^{\circ} \mathrm{C}$. In Fig. 12 , some results on the change of oxygen content of the iron during rephosphorization are also shown. Calculated mass transfer coefficients of oxygen were from $0.9 \times$ $10^{-2}$ to $1.5 \times 10^{-2} \mathrm{~cm} / \mathrm{sec}$, nearly the same with the value obtained in the experiment without phosphorus transfer. This fact would indicate that the oxygen transfers faster than phosphorus and has little influence on the rate of phosphorus transfer.

\section{Conclusion}

The rates of dephosphorization and rephosphorization of iron melt were obtained from the change of the phosphorus contents of the metal and the slag contained in the magnesia crucible. Experiments were made on the slags of basicity from 0.57 to 1.76 at temperature from $1570^{\circ}$ to $1680^{\circ} \mathrm{C}$.

The reaction proceeded so fast that the phosphorus content in iron reached a constant value within about $20 \mathrm{~min}$. It was lower with more basic slag and at 


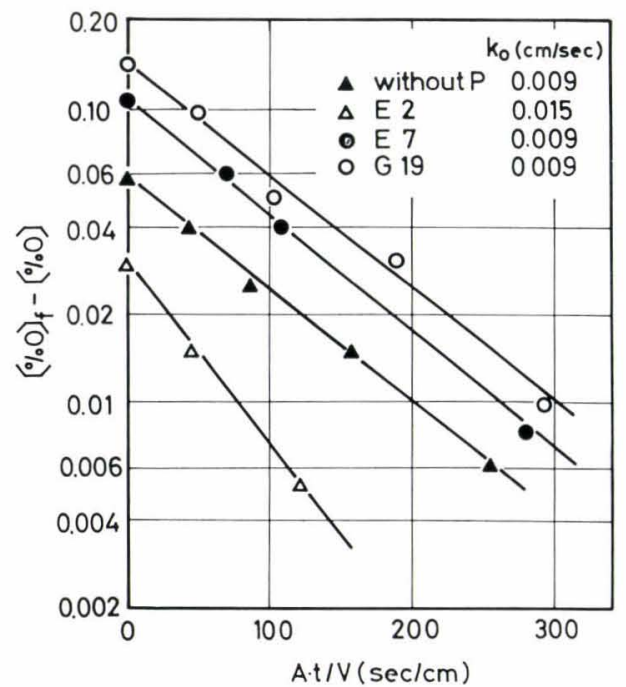

Fig. 12. Relation between $\left([\% \mathrm{O}]_{f}-[\% \mathrm{O}]\right)$ and $A \cdot t / V$

lower temperature.

The rate of dephosphorization was higher with the more basic slag, while the rate of rephosphorization was lower. The effect of temperature was negligible for the dephosphorization, whereas the rate of rephosphorization increased with temperature.

These results were interpreted by the model of mass-transfer-controlled reaction. It was found that the rate-controlling step was in both slag and metal phases for the dephosphorization and only in the metal phase for the rephosphorization. Mass transfer coefficient $k_{\mathrm{s}}$ was from $0.47 \times 10^{-3}$ to $4.3 \times 10^{-3} \mathrm{~cm} / \mathrm{sec}$ and $k_{\mathrm{m}}$ was from $0.33 \times 10^{-2}$ to $1.09 \times 10^{-2} \mathrm{~cm} / \mathrm{sec}$.

\section{REFERENCES}

1) E. T. Turkdogan and J. Pearson: JISI, 175 (1953), 398.

2) G. W. Healy: JISI, 208 (1970), 664.

3) F. Aratani and K. Sanbongi: Tetsu-to-Hagané, 58 (1972), 1225.

4) P. Kozakevitch: Rev. Mét., 46 (1949), 505.

5) K-H. Klein, H. Abratis, H. Maas and M. Wahlster: Arch. Eisenhüttenw., 45 (1974), 9. 